\title{
Expanding the Conceptual and Analytical Basis of Energy Justice: Beyond the Three-Tenet Framework
}

\author{
Joohee Lee ${ }^{1,2 *}$ and John Byrne ${ }^{1,2,3}$ \\ ${ }^{1}$ Center for Energy and Environmental Policy, University of Delaware, Newark, DE, United States, ${ }^{2}$ Foundation for Renewable \\ Energy and Environment, New York, NY, United States, ${ }^{3}$ School of Advanced International Studies, Johns Hopkins University, \\ Washington, DC, United States
}

OPEN ACCESS

Edited by:

Alevgul H. Sorman,

Basque Centre for Climate

Change, Spain

Reviewed by:

Jenny Lieu,

ETH Zürich, Switzerland

Siddharth Sareen,

University of Bergen, Norway

*Correspondence: Joohee Lee jhlee@udel.edu

Specialty section:

This article was submitted to Energy Systems and Policy,

a section of the journal

Frontiers in Energy Research

Received: 14 October 2018

Accepted: 30 August 2019

Published: 26 September 2019

Citation:

Lee J and Byrne J (2019) Expanding the Conceptual and Analytical Basis of

Energy Justice: Beyond the

Three-Tenet Framework.

Front. Energy Res. 7:99.

doi: 10.3389/fenrg.2019.00099
Energy justice is now an established research topic in the field of energy policy. Despite the growing popularity of energy justice research, however, conceptual and analytical frameworks used in the field have remained limited. This paper reviews the prevailing three-tenet framework of energy justice which has shaped the current discourse based on the three dimensions-distributional, procedural, and recognition justice. As an effort to contribute to expanding the research agenda of energy justice problems, we propose a new understanding of the production of energy injustice by characterizing three institutionalized tendencies of dominant modern energy systems: (1) preference for large-scale technical systems and distancing of system designs from local decision-making processes, (2) centralization of energy production and concomitant distancing of supply from users, and (3) widespread 'risk-taking' tendencies portrayed by designers and proponents of current energy supply systems as a necessary 'price to pay' for technological innovation and social progress. We then connect these three tendencies to political, economic, and technical ideologies of modernism that often provide justifications for energy inequity: (1) top-down political and economic decision-making systems, (2) technical interpretation of sustainability, (3) specialist understanding of fairness, and (4) path dependency in the modern energy paradigm. Finally, we present an illustration of how this new conception of systemic energy injustice can be applied in practice using the case of South Korea's nuclear power system and Seoul's One Less Nuclear Power Plant Initiative.

Keywords: energy justice, three-tenet framework, systemic analysis of energy injustice, nuclear power, South Korea, Seoul, One Less Nuclear Power Plant initiative

\section{INTRODUCTION}

The fast growth of energy markets throughout the twentieth century has been widely interpreted as an essential ingredient of economic development (see, for example, the "energy-civilization" equation mapped by Basalla, 1980). Ignoring Basalla's plea for a social discussion of energy sector characteristics, researchers and policymakers have too frequently treated energy as a technical and economic concern (Stern and Aronson, 1984). However, mounting problems traceable to energy operations-including climate change, energy poverty, and widespread use of risky ${ }^{1}$ energy

\footnotetext{
${ }^{1}$ For this paper, the term 'risk' refers to social and environmental harms that can result from the siting and operation of energy facilities. Risks can include health concerns, decreased quality of life, economic disadvantages (e.g., decreased property values), exposure to hazards and accidents, etc.
} 
technologies-have caused the re-emergence of social considerations that reach beyond standard technological or economic analysis. Indeed, many researchers now underscore the importance of analyzing "energy as a social project" (Byrne et al., 2006, 2009; Goldthau and Sovacool, 2012; Sovacool et al., 2016).

Equity challenges in modern energy governance have fostered work on energy justice concepts and studies. But the research has focused mainly on fuel poverty topics. Our aim is to contribute to an expanded research agenda of energy justice studies. The so-called "three-tenet" framework that has anchored the current discourse emphasizes distributional, procedural, and recognition justice issues. It has been widely applied to energy justice analyses (Walker and Day, 2012; McCauley et al., 2013) although there is a growing body of research that recognizes the need to improve it (Forsyth, 2014; Jenkins et al., 2014; Jamal and Hales, 2016). We welcome the contemplated improvements but would offer that additional research on structural and ideological components of energy injustice is needed. In this vein, the paper offers a systemic framework for understanding injustices associated with energy production. $^{2}$

In order to explain the conceptual challenge, we begin with a discussion of the three-tenet framework and notable points of progress made under its guideline. We then propose a new understanding of energy justice problems as outcomes of tendencies to prefer large-scale and centralized energy system designs, to distance decision-making processes from users, and to regard technological risks as a necessary 'price to pay.' To illustrate how the new approach can apply in practice, we present an analysis of South Korea's nuclear power system and differential risks it creates across socioeconomic groups and geographies. Justice conflicts and tensions associated with nuclear plant siting and operations in Korea have been discussed in many studies over the past 20 years (see, for example, Kim and Byrne, 1996; Valentine and Sovacool, 2010; Lee et al., 2018; Park and Sovacool, 2018). We then review the City of Seoul's efforts to contest the differential risks through an energy justice-oriented, lowcarbon initiative.

\section{THE THREE-TENET FRAMEWORK OF ENERGY JUSTICE}

The conceptual sophistication of environmental justice work over the last 40 years has spawned efforts to apply lessons to a widening scope of concerns (Hobson, 2006; Agyeman et al., 2016). The rise of 'energy justice' can be understood as part of this evolution. Since its emergence, energy justice has seen a notable expansion in academic research (Sovacool and Dworkin, 2015), particularly raising important questions on the role of energy institutions to address widening poverty gaps and corresponding difficulties in energy due to mounting unaffordability.

Despite the growing popularity of energy justice research, conceptual and analytical frameworks used in the field have mostly focused on social conditions and processes, with less

\footnotetext{
${ }^{2}$ We are developing a paper to investigate a systemic framework for understanding injustice related to energy consumption and policy's role in addressing the nature and patterns of this form of energy injustice.
}

attention to underlying economic and political structures and institutions. For example, many studies have employed the three-tenet justice framework to characterize and analyze ethical debates about energy (Heffron and McCauley, 2014, 2017; Jenkins et al., 2016). The framework was initially adapted from environmental justice research and is predicated on three principles-distributional, procedural, and recognition justicewhich foster analyses of unfair energy policies and projects. Below is a brief review of the three tenets applied to energy (Walker and Day, 2012; Heffron and McCauley, 2014).

Distributional justice concerns unfairness in the process of sharing costs and benefits created by energy development across society. Fuel poverty is one type of distributional injustice which results from the combination of inequalities in income, energy prices, and housing conditions. Procedural justice calls for equitable and democratic involvement of all stakeholders in energy decision-making. Full information disclosure and proper policy mechanisms to encourage public participation are essential to achieving procedural justice. Recognition justice emphasizes the need to understand different types of vulnerability and specific needs associated with energy services among social groups (especially marginalized communities).

While the three-tenet framework provides a conceptual backbone for identifying and analyzing problems with regard to common energy (including fuel poverty), it does not directly address complex political and economic forces that routinely produce energy injustice. The framework tends to shed more light on 'tailpipe' problems and fixes like improved accessibility and affordability while leaving the structural and ideological pillars of the problem under-examined. ${ }^{3}$ For this reason, energy poverty is usually the analytical boundary for discussions of energy justice (Bouzarovski and Simcock, 2017).

While energy justice is rightly tied to energy poverty problems, the language can limit problem identification, the scope of investigations, and the type of analysis pursued regarding energy justice issues. Broader topics involving justice implications of modern energy systems as a whole are needed (Bickerstaff et al., 2013; Jenkins et al., 2014; Joroff, 2018). In the following section, we argue that energy justice frameworks should also recognize external driving forces of injustice beyond the three justice dimensions of the prevailing framework.

\section{THE PRODUCTION OF ENERGY INJUSTICE}

Byrne et al. (2002) argued that contemporary environmental problems are a product of our changing nature-society relations. In their work, they highlighted three phases of the commodification of nature-normalization of pollution, technocratic authoritarianism, and a rise of the Anthropocene. Throughout these three evolving and concurring phases, environmental injustice does not randomly 'occur' but rather is '(re)produced' habitually. Industrial economies have been busy looking for measures to alleviate what is often called

${ }^{3}$ The structural and ideological pillars of modern energy systems are discussed in detail in section The Production of Energy Injustice and are depicted in Figure 1. 


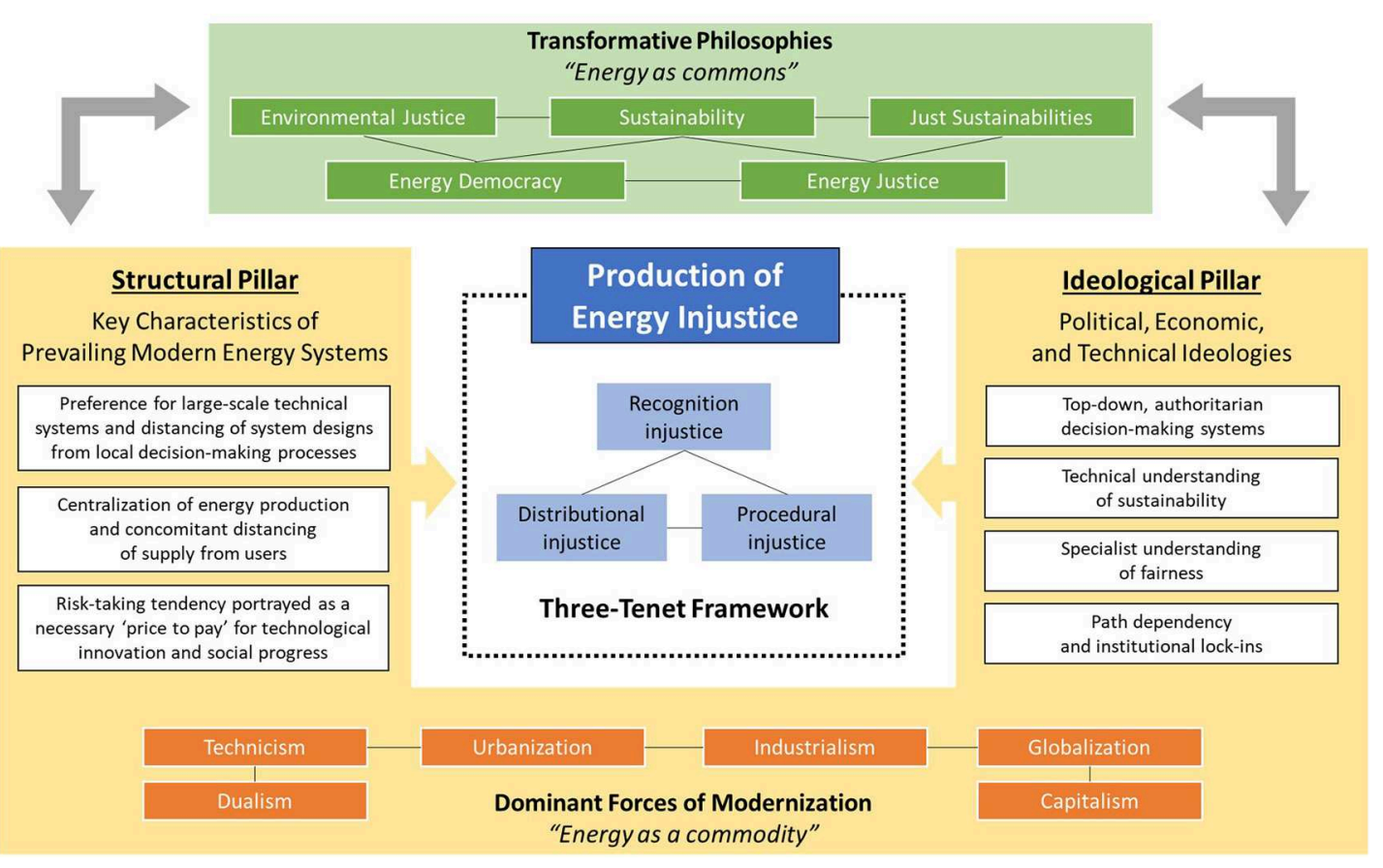

FIGURE 1 | Conceptual framework for understanding the production of systemic energy injustice.

environmental 'externality' (see Coase, 1960). But this treatment of the problem presumes that human ability to re-design and replace ecosystems is a step toward the creation of an improved nature.' In this way of thinking, environmental problems and conflicts are temporary matters awaiting human repair. The implication of the assumed duality of a natural reality and social one is not usually questioned.

Applied to modern energy supply systems, this way of thinking normalizes environmental and social consequences of energy projects that operate on principles of industrialism, technicism, and capitalism (Mumford, 1934; Byrne et al., 2006). Energy injustice, in this view, is an expectable outcome of economic progress and should be addressed rationally by reducing its spread, but only so long as it is economically optimal to do so.

To address energy injustice, it is crucial to grasp how conflicts are institutionalized in the structure of our energy systems (Sareen and Haarstad, 2018). In what follows, we introduce a new view of the 'production of energy injustice' based on the idea of the "production of unequal nature" found in Byrne et al. (2002). Our argument is that political, economic, and technical ideologies ${ }^{4}$, borne out of the three phases of commodification noted above, routinely rationalize energy-sourced justice

\footnotetext{
${ }^{4}$ The term 'ideology' used in this paper relies on Mannheim (1985)'s definitionideologies are constellations of ideas that allow our current reality to make sense. For example, during the rise of industrialism and capitalism, societies learned the importance of markets, prices, and regulations in ways that are not the same for a feudal era. Likewise, the ideologies highlighted in our conceptual framework are political, economic, and technical contexts prevalent in the industrialized world that allow modern energy systems to make sense and that lead citizens and policymakers to assume that energy-sourced social problems will be resolved.
}

conflicts as the unfortunate but necessary results of industrial success. Instead, we propose research on risks and harms of energy supply as justice issues that require attention at the system scale.

We focus here on the prevailing forms of modern energy supply that serve industrial societies, including coal and nuclear power plants. These facilities tend to have greater, and possibly irreversible, impacts on nearby communities and the environment. The Environmental Justice Atlas (Temper et al., 2015) reports more than 100 ongoing injustice cases resulting from the use of nuclear energy across the globe. When energy injustice categories are expanded to include fossil fuels and climate issues, the number of cases grows tenfold. Undoing these energy options is needed as much as installing renewables in order to achieve a higher level of energy equity (Byrne et al., 2006; David, 2018).

As depicted in Figure 1, two interlinked 'pillars' create systemic energy injustice: (a) key design characteristics of dominant energy systems, which are direct sources of energy inequity (what we term a structural pillar) and (b) political, economic, and technical ideologies ${ }^{5}$ which provide justifications for energy inequity (an ideological pillar). Below we explore both pillars of energy injustice.
${ }^{5}$ Political, economic, and technical forces are closely interlinked as sources of power and agenda-setting in policy decision-making. Often, it is difficult to draw a clear line between them. In this paper, our focus is on large-scale, centralized, and risky energy technologies. The modern preference for them is often expressed in economic terms (e.g., lower cost and 'efficient' choice). But this preference requires significant political and policy support early on in the development of modern energy supply systems (including the creation of regulated markets for utility monopolies with guaranteed rates of return). 


\section{Structural Pillar of Energy Injustice}

The first key characteristic of the modern energy system is its preference for large-scale technical systems and distancing of system designs from local decision-making processes (Sovacool et al., 2018). This tendency relates closely to the core value of industrialism-'efficiency.' Placing a greater emphasis on efficiency, industrial societies have faithfully equated social progress with economic growth driven by technological breakthroughs. In particular, the energy sector has pursued large-scale development with the aim of realizing higher efficiency in production. Like other industries and sectors, a scale principle is at the center of modern energy economics, resulting in massive production of energy units (kWhs, therms, etc.) with sources such as coal and nuclear energy favored despite their known health and environmental harms (Sovacool et al., 2014). In modern energy's history, the ability to produce much more energy at a lower cost is paramount; the purposes and use of this energy surplus, and more broadly, its value to society, is a secondary concern. A form of Say's Law (Sowell, 1972) in which energy supply will create its own demand is expected to guide thinking. As the scale of energy production and consumption has grown, major energy decisions and management have become the preserve of science, engineering, and macroeconomics. Citizens devolve to passive consumers, deprived of control over their energy choices. ${ }^{6}$

The second defining characteristic is the centralization of energy production and concomitant distancing of supply from users. Energy production from large power plants is widely assumed to deliver lowest-cost power in the technical sense. The social and governance implications of this design go mostly unexamined (at least until recently). The centralization of energy supply can be conceived as a concomitant outcome of largescale development. For example, scale-up of energy production tends to force the periphery (e.g., suburban areas, economically and/or politically less privileged communities, etc.) to host energy facilities with a mission to export energy services to privileged communities. $^{7}$

Regional planners frequently think that placing large-scale systems such as nuclear power plants near users is risky and socially undesired. ${ }^{8}$ As a result, an enormous amount of energy consumption takes place in urbanized and wealthy areas, as production facilities and distribution networks are sited in rural areas (or, in some cases, 'depressed' urban locales), creating a geography of technical efficiency and, at the same time, social and environmental injustice. Research shows a pattern in the modern energy build-out that allocates risks disproportionately

\footnotetext{
${ }^{6}$ It is important to mention that small-scale energy production can also involve energy justice conflicts. Figure 1 does not intend to rule out this possibility. Rather, the diagram is structured to analyze the tendency to prefer large-scale energy infrastructures that can lead to serious and society-wide conflicts across geographies as well as generations.

${ }^{7} \mathrm{We}$ do not assume intentionality to this process when recognizing the effective social and governance consequences of energy centralization.

${ }^{8}$ Engineers and scientists who design nuclear power plants agree with this thinking-see section South Korea's Nuclear Power Build-out as a Case of Systemic Energy Injustice.
}

to the periphery (UCC, 1987; Touché and Rogers, 2005; Luna, 2008; NAACP, 2012; Ji et al., 2015). As social awareness grows about this pattern, technical solutions such as 'green growth', 'clean coal', and 'inherently safe nuclear power' are being found by researchers to actually lead to deepening inequality and unsustainability (Byrne et al., 2006, 2009; Richardson, 2017; Ha and Byrne, 2019).

A third characteristic of the modern energy system is its widespread 'risk-taking' tendency, which is portrayed as a necessary 'price to pay' for technological innovation and social progress (Byrne et al., 2002). Modern energy systems are distinctive for their acceptance of principles of "necessary risk" and "normal accidents" as highlighted in Beck (1992) and Perrow (1984). Energy systems and services inevitably involve high levels of risk during construction, operation, and maintenance of facilities. However, an under-estimation of risks and an under-valuation of social and environmental costs are hallmarks of energy technologies from nuclear and coal power plants to oil refineries, and natural gas and oil pipelines.

The Fukushima nuclear accident explicitly illustrates this kind of risk-taking. When a record-breaking earthquake struck Japan in 2011, the Tokyo Electric Power Company (the operator of the troubled nuclear reactors) and the Japanese government poorly communicated with the public that it was an inevitable and unpreventable accident and that the radiation releases would not immediately affect health (Faculty of Societal Safety Sciences, 2018). However, it is questionable whether only immediate and visible consequences deserve our concern given that approximately 165,000 people were evacuated from regions and deprived of the right to sustain their normal life (CNIC, 2017).

\section{Ideological Pillar of Energy Injustice}

As illustrated in Figure 1, these structural characteristics of the modern energy system are reinforced by political, economic, and technical ideologies that have dominated the reasoning of policy decisions in industrial societies.

An example is top-down, authoritarian decision-making that often serves as a powerful political tool for the technical rationalization of large-scale energy facilities at the expense of their social impacts. Sometimes, large-scale energy projects create energy inequality for particular stakeholders because the physical complexity and massive scale of economic investment have often preempted non-technical and non-economic reasoning and valuations from being involved in decision-making processes [see Hughes (1983) for the classical study on the rise of electric power systems in western society]. This preemption tendency has been observed by researchers studying largescale and centralized energy projects over the last 40 years (Messing et al., 1979; Stern and Aronson, 1984; Byrne and Hoffman, 1996; Sovacool et al., 2016; Cherp et al., 2018). A consequence of technical and economic authoritarianism is marginalization of social values in energy decisions, leading specifically to the widening of energy injustice, as a recent special issue on the topic discusses (Bridge et al., 2018). For 
this reason, local communities and underserved populations who usually have less power cannot effectively question, much less resist, technocratic preemption in which specialized knowledge enlisted on behalf of the sector often reduces public hearings to exercises of expert authority determining what is best for 'uninformed' citizens.

An additional example is sustainability, which as an ideal is supposed to lift public decision-making above technical and economic recitations of value. But the ideal has often been captured by consultants, modelers, and planners who argue that sustainability requires a technical understanding of our problems and is therefore best left for experts to decipher. For instance, the concept of 'green growth', which was supposed to be rooted in a new discourse of sustainable development, today usually relies heavily on technological solutions to energy problems without taking justice implications seriously (Ha and Byrne, 2019). Advocates of green growth consider technologies like nuclear energy as an ideal option to reduce greenhouse gas emissions and fortify national security without compromising economic growth. Safety issues associated with nuclear power, the presence of high levels of embodied carbon emissions in the life cycle of nuclear plant operations, and the disenfranchisement of citizen governance are treated as the necessary price of comprehensive solutions. In opposition to this 'technical' interpretation of sustainability, more advanced and justice-driven discourses such as 'just sustainabilities' have emerged (Byrne et al., 1998; Agyeman, 2013). These discourses call for a careful consideration of the justice implications of energy, climate, or environmental decisions.

Third, a specialist understanding of fairness frequently underpins modern thinking (Byrne et al., 2002) in which the question of justice is thought to be largely a debate about the rational and objective level of compensation for victims harmed by energy operations. Closing plants that contribute to risks or planning for systems that can be governed by citizens are thought by some to be naive and, even, reckless ideas. One example is the way in which the problem of energy poverty is portrayed and approached. Many of the existing solutions to energy poverty are focused on fuel payment subsidies that can, at most, temporarily alleviate the problem. Such programs can be sometimes used to justify continued reliance on large-scale and carbon-intensive energy technologies that have imposed serious environmental and social conflicts in people's livelihoods but, on technical grounds, are conceived as as 'efficient' and 'cost-effective.'

Finally, there is a significant level of path dependency in the modern energy paradigm (Bridge et al., 2013). Conventional energy infrastructures demand an enormous amount of investment and need the commitment of policy support in order to ensure their economic legitimacy among investors. Delivering such legitimacy requires forms of decision-making that can convince society there is little choice but to support the continuous build-out of conventional energy infrastructure. Anything less is believed to imperil economic development and social progress. Predictably, constrained decision-making of this kind often leads to institutional lock-ins that intensify the tendency to maintain energy-intensive economies relying on centralized and inherently risky energy technologies (Byrne et al., 2009), while promising more sophisticated management and oversight.

\section{SOUTH KOREA'S NUCLEAR POWER BUILD-OUT AS A CASE OF SYSTEMIC ENERGY INJUSTICE}

A systemic analysis of South Korea's commitment to nuclear power and its energy justice implications is performed to offer insights about energy justice that reach beyond those of the three-tenet framework. The case of South Korea is presented as an example of how systemic analysis can be fruitfully deployed.

To realize a fast-growing economy, South Korea's leadership made a commitment to energy-intensive manufacturing beginning in the 1950s. This commitment led to the construction of a highly centralized and large-capacity electricity supply system (Valentine and Sovacool, 2010; Lee et al., 2018). The 11 th largest economy in the world is now powered by 61 coal power plants and 24 nuclear reactors. The role of nuclear power is particularly notable in South Korea's commitment to 'energy giantism' (Byrne et al., 2006). Nearly 30\% of South Korea's electricity demand is met from nuclear power plants located well-outside the boundary of the country's major electricity consumer-metropolitan Seoul (Yun, 2017). The distancing of the nuclear power plant network far from Seoul was planned from the outset (Kim and Byrne, 1996; Park and Sovacool, 2018). The decision shifted a host of risks associated with energy operations generally and nuclear generation specifically to other parts of the country that often are "geographically remote, economically marginal, politically powerless" (Park and Sovacool, 2018, p. 686).

Is this shift an indication of energy injustice? To answer the question, we need to establish the relationship among three variables: proximity to nuclear plants, risk of harm from nuclear plant operations and accidents, and socioeconomic vulnerability of communities near plants compared to those that are not near plants. ${ }^{9}$ Specifically, is proximity to nuclear plants a key predictor of risk of harm from their operation? And if so, is socioeconomic status a key predictor of who is at greatest risk of harm due to proximity to the plant network?

Regarding the first relationship of proximity and harm, international emergency planning is based on risk of harm from nuclear plants being inversely proportional to plant proximity. For instance, the largest U.S. emergency planning zone standard is an $80 \mathrm{~km}$ radius around a plant (U.S. NRC, 2017). The International Atomic Energy Agency (IAEA) has defined an urgent protective action planning zone standard of $30 \mathrm{~km}$ in radius for plants in general (IAEA, 2007). ${ }^{10}$ These standards anticipate

\footnotetext{
${ }^{9}$ These variables are commonly used in environmental justice studies. See Cutter et al. (2003). The U.S. Environmental Protection Agency (EPA)'s EJSCREEN, an environmental justice mapping and screening tool, also includes these indicators for identifying unequal risk of harm (U.S. EPA, 2017).

${ }^{10}$ South Korea follows the IAEA standard for emergency planning of $30 \mathrm{~km}$ (NSSC, 2014).
} 
evacuation within their defined zones depending on the level of severity of a disaster. Recently, an international effort led by the U.S. National Academies of Science, Engineering, and Medicine (NASEM, 2016; see also Lyman et al., 2017) has sought to understand from the Fukushima nuclear accident the health and safety risks associated with nuclear plant operations. This work has led to the finding that for certain accidents, an extension of the evacuation zone is needed to $110-170 \mathrm{~km}$ (NASEM, 2016, 40-41 and 178-183; and Lyman et al., 2017).

Relying on the findings of the U.S. NRC, IAEA, and NASEM on the relationship between risk of harm and plant proximity to guide our case study, we then turned our focus to the second relationship, namely, socioeconomic vulnerability and plant proximity. Socioeconomic vulnerability is measured by county average housing price. ${ }^{11}$ Data for income per capita or per household are not available at the county level in South Korea.

Results of two regression analyses of the relationship between socioeconomic vulnerability and nuclear plant proximity are reported here. Data were collected from the Korea Appraisal Board's database (http://www.r-one.co.kr/) for all counties reporting average housing prices for the period 2012-2016 (a total of 154 counties). ${ }^{12}$ We then used the average of the 5 years county average housing prices as the independent variable. ${ }^{13}$ Proximity to the nearest nuclear power station was calculated using ArcMap 10.4 and was used as the dependent variable.

A regression study of the relationship between average housing value and nuclear plant proximity for 154 counties was prepared in order to understand if socioeconomic vulnerability could predict plant proximity. Statistical robustness of the prediction was measured by a commonly used tool, the coefficient of determination (or $\mathrm{R}^{2}$ ). Among several regression models that we considered, reported here is the model we believe is best suited for prediction of a general relationship between socioeconomic vulnerability and nuclear plant proximity. The selected model assumes an underlying logistic

\footnotetext{
${ }^{11}$ In the absence of detailed income data, housing price is recognized by many as a reasonable proxy. For example, the World Bank suggests several proxy measures including housing value (O’Donnell et al., 2008). See also UNDP (2017). Housing prices are affected by a number of factors including physical characteristics of the property (e.g., living area, number of rooms, etc.) and living conditions around the property (e.g., environmental quality, amenities, safety, etc.). Previous studies examined the relationship between power station locations and local property values (Clark and Nieves, 1994; Folland and Hough, 2000; Davis, 2011). It is important to note that apartment prices used for this study are the average value for each county. This average is far less affected by physical or other characteristics of individual properties. Average housing price data by county were available for most but not all counties. Data were missing for some rural areas, located in the southern and eastern parts of the country. If data were available, it is probable that the strength of the statistical finding of energy injustice would increase. Typically, Koreans live in multi-floor, multi-family rather than single-family buildings and own their apartments rather than rent them.

${ }^{12}$ Jeju province, an island off the southern coast of the mainland of South Korea, was excluded from this case study as the majority of its electricity supply comes from power stations located in the island.

${ }^{13}$ Average housing prices for a defined spatial area typically do not change greatly over a short period. Still, it is common practice to use short-term averages in order to avoid undue influence of outliers.
}

function among the two variables. ${ }^{14}$ We employed OriginLab software (https://www.originlab.com/) and KNIME software (https://www.knime.com/knime-software) to partition the 154 counties into clusters based on statistically measured "feature similarity" (Malik and Tuckfield, 2019). We found three clusters could most efficiently represent the data. This model was able to account for $96 \%$ of the variation in county proximity to a nuclear plant by knowing county average housing price (see the top regression in Figure 2). The results provide a clear basis for understanding that distance to a nuclear plant is inversely related to a county's extent of socioeconomic vulnerability.

A second regression study was then formulated to examine directly the systemic character of energy injustice embodied in the layout and operations of the South Korean nuclear plant network. We identified the counties within $80 \mathrm{~km}$ of South Korea's nuclear reactors for which county average housing price data are available (a total of 60 counties). ${ }^{15}$ We added to the database for the second regression the 25 counties of Seoul, all of whose families live beyond $170 \mathrm{~km}$ from a nuclear power plant. ${ }^{16}$ Our focus on Seoul and the counties in the potential evacuation zone is based on a core energy justice principle: who bears the risks of harm by the operations of an energy plant network and who receives the benefits. Seoul's counties have the highest per capita residential electricity consumption in the country; the counties in the evacuation zone bear the greatest risk of harm from nuclear power operations.

Using OriginLab software, we again tested several regression models to predict nuclear plant proximity by socioeconomic vulnerability and found statistically robust predictability. We report here a sigmoid growth $\operatorname{model}^{17}$ depicting a pronounced inverse relationship between socioeconomic status and risk of harm that can explain $86 \%$ of the variation in the variables (see the lower regression panel in Figure 2).

A systemic pattern of energy injustice is evident: those at greatest risk of harm from the nuclear plant network (that is, families living in the internationally defined emergency planning zones of South Korea) have high levels of socioeconomic

\footnotetext{
${ }^{14}$ Generally, logistic regression treats the dependent variable (here, nuclear plant proximity) as broadly binary. In this case study, high socioeconomic vulnerability, characterized by persistently well-below average county housing prices, is expected to be statistically different to a state of low socioeconomic vulnerability (represented by communities with statistically well-above average housing prices); and these two clusters are expected to be statistically better predictors of nuclear plant proximity. Vulnerable communities not in the potential evacuation zone but not beyond $170 \mathrm{~km}$ from a plant (represented as gray data points in Figure 2) are expected to be less reliably predictive of nuclear plant proximity.

${ }^{15}$ Housing price data are not available for 35 counties in the U.S. NRC-defined emergency planning zone. Nearly all of these counties are rural in character.

${ }^{16}$ Only counties of metropolitan Seoul (including Gyeonggi province and Incheon) live beyond the $170 \mathrm{~km}$ boundary identified by NASEM (2016) for post-Fukushima evacuation planning. The residents of Gyeonggi and Incheon consume much less residential electricity per capita and are hosts of fossil fuel plants, raising a different energy justice question (which we are studying).

${ }^{17}$ This model is a classic form of generalized logistic regression expecting an $\mathrm{S}$-shaped (sigmoid) function in the data.
} 

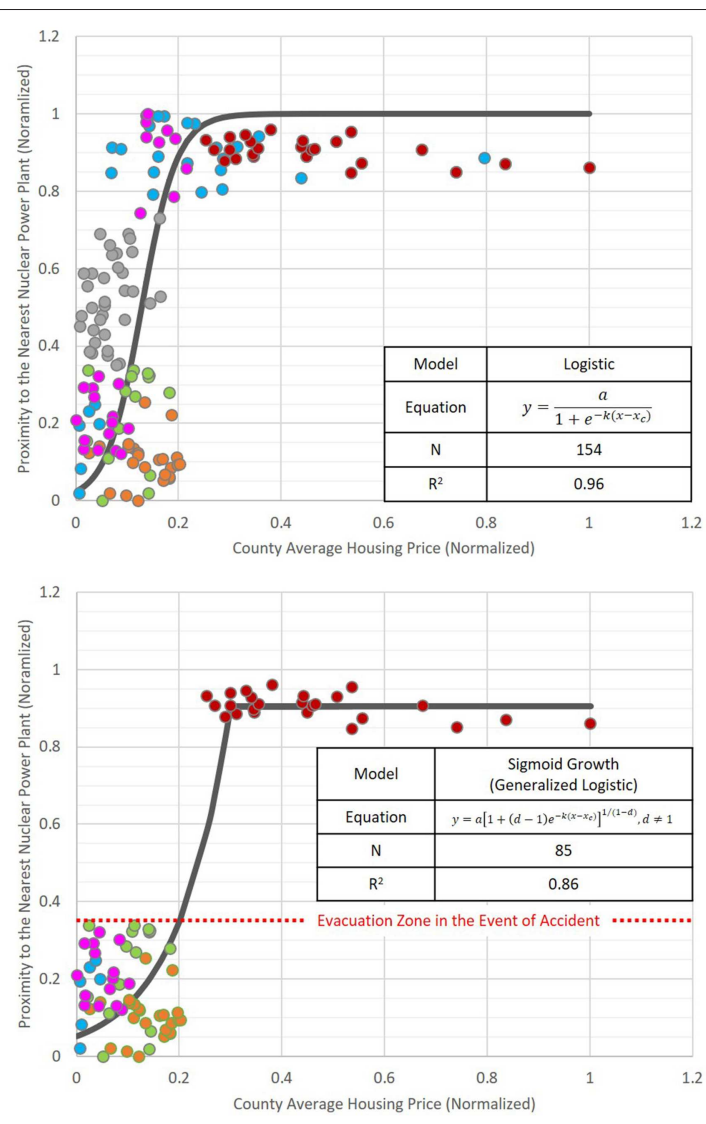

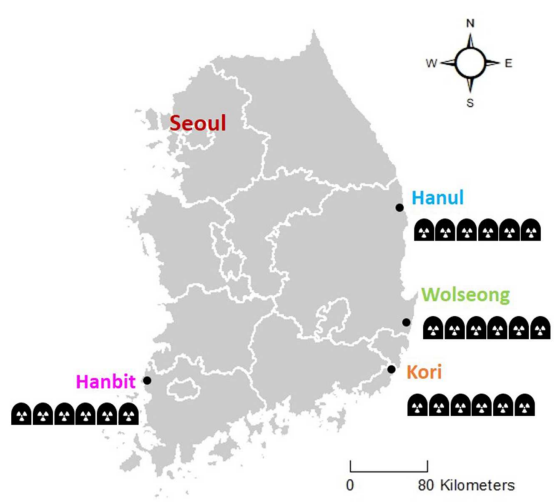

Locations of nuclear power plants in South Korea

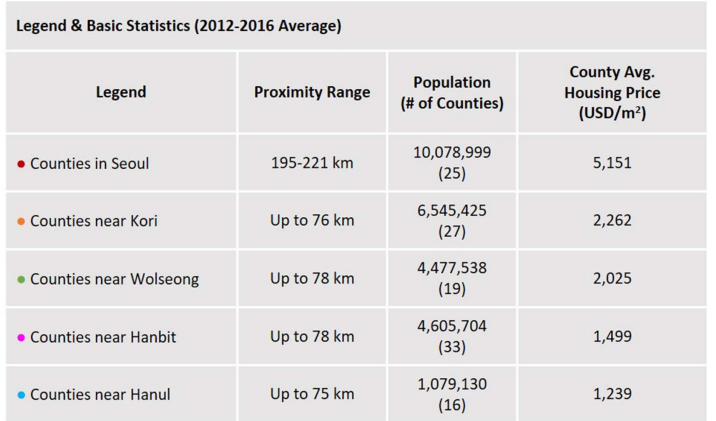

FIGURE 2 | Regressions of county average housing price to predict nuclear plant proximity in South Korea.

vulnerability and are mostly in the third or lower decile in electricity consumption per capita; Seoul's families are in the top decile of electricity consumption per capita, reaping significant benefits of the nuclear network's output, but all live beyond even the post-Fukushima definition of evacuation risk.

As well, it is important to consider one feature of the risk that communities near the country's plants face: even when families are fortunate to have been spared cancer and deadly explosions, they are at risk of losing their homes and livelihoods in the event of a plant disaster including the release of radioactive emissions, the migration of radioactive waste, accidents involving the transport of waste, etc. (as families experienced in the wake of the Chernobyl and Fukushima accidents).

Actions to compensate families for the risks they face, greater attention to evacuation planning in the event of accidents, empowering communities to play substantive roles in governing the energy system, and other policy steps should be considered in order to address the energy justice problem. But the energy injustice embedded in the nuclear power plant network itself cannot be solved by these methods alone. Structural and ideological drivers deeply rooted in the modern energy paradigm are 'engines' of the problem as depicted in Figure $\mathbf{1}$.

Only actions aimed at pursuing systemic change can actually meet the challenge. In the next section, we briefly review an action of this kind-the One Less Nuclear Power Plant movement in Seoul.

\section{RESPONDING TO SYSTEMIC ENERGY INJUSTICE: SEOUL'S ENERGY JUSTICE-ORIENTED, LOW-CARBON TRANSITION STRATEGY}

In 2012, the Mayor of Seoul launched a transformative energy initiative which he named "One Less Nuclear Power Plant (ONLPP)." A key goal of this initiative is to challenge national and city dependence on nuclear and coal power by using aggressive conservation policies to cut energy consumption and greenhouse gas emissions levels, and also by calling for enhanced self-sufficiency of electricity through solar power development (SMG, 2018). What makes the OLNPP distinctive is its explicit recognition of energy injustice embedded in the country's largescale and centralized energy supply systems that have placed environmental and health risks on the shoulders of vulnerable populations (Ahn, 2017).

Designed to tackle this path dependency of inequitable and unsustainable energy development, the initiative achieved early success, enabling a reduction in energy demand equal to one 
nuclear plant in just three years (SMG, 2018). The initiative is currently in its second phase and announced the "Solar City Seoul" project that aims to deploy one gigawatt of distributed solar photovoltaic systems throughout the city by 2022 (Kang, 2018). The OLNPP suggests how the social imaginary of sustainable energy paths can be embodied at a local scale and can be driven by energy justice principles.

In opposition to structural and ideological drivers that create and perpetuate energy injustice, transformative actions like Seoul's OLNPP initiative have received conceptual standing as 'just sustainabilities' and 'energy democracy' experiments (Burke and Stephens, 2017; Yun, 2017; Teron and Ekoh, 2018; Yun et al., 2018). An increasing number of civil society movements now recognize the importance of treating energy systems as social, political, and ethical questions (Piggot, 2018). An emerging agenda for social science is to support research on energy justice initiatives that address systemic conflicts and problems.

\section{CONCLUSION}

Restoring the recognition of energy as a social project is the initial step to challenge and self-criticize institutionalized mechanisms of the production of energy injustice and its path dependency. Byrne et al. (2006) share this viewpoint that "building an inquiry into energy as a social project will require the recovery of a critical voice that can interrogate, rather than concede, the discourse's current moorings in technological politics and capitalist political economy," and that "a fertile direction in this regard is to investigate an energy-society order in which energy systems evolve in response to social values and goals, and not

\section{REFERENCES}

Agyeman, J. (2013). Introducing Just Sustainabilities: Policy, Planning, and Practice. London: Zedbooks.

Agyeman, J., Schlosberg, D., Craven, L., and Matthews, C. (2016). Trends and directions in environmental justice: from inequity to everyday life, community, and just sustainabilities. Annu. Rev. Environ. Resour. 41, 321-340. doi: 10.1146/annurev-environ-110615-090052

Ahn, B. (2017). "One less nuclear power plant: a case study of seoul megacity," in Reframing Urban Energy Policy: Challenges and Opportunities in the City of Seoul (Seoul: Seoul Metropolitan Government), 86-119.

Basalla, G. (1980). Energy and Civilization. Science, Technology and the Human Prospect. New York, NY: Pergamon Press.

Beck, U. (1992). Risk Society: Towards a New Modernity. London: Sage Publications.

Bickerstaff, K., Walker, G., and Bulkeley, H. (2013). Energy Justice in a Changing Climate: Social Equity and Low-Carbon Energy. London: Zed Books.

Bouzarovski, S., and Simcock, N. (2017). Spatializing energy justice. Energy Policy 107, 640-648. doi: 10.1016/j.enpol.2017.03.064

Bridge, G., Bouzarovski, S., Bradshaw, M., and Eyre, N. (2013). Geographies of energy transition: Space, place and the low-carbon economy. Energy Policy 53, 331-340. doi: 10.1016/j.enpol.2012.10.066

Bridge, G., Özkaynak, B., and Turhan, E. (2018). Energy infrastructure and the fate of the nation: Introduction to special issue. Energy Res. Soc. Sci. 41, 1-11. doi: 10.1016/j.erss.2018.04.029 simply according to the dictates of technique, prices, or capital (p. 23)." Indeed, the role of social sciences in energy research is considered increasingly critical in the shaping of future energy paths (Pasqualetti and Brown, 2014; Ryan et al., 2014; Sovacool et al., 2015).

In this vein, we have proposed a conceptual and analytical framework that can shed light on underlying drivers of energy injustice embedded in the dominant modern energy paradigm. We hope this framework can help researchers reconsider the conventional way of framing energy justice problems. The case of Seoul's justice- and value-centered energy initiative illustrates the potential of energy justice principles as a catalyst for sustainable and low-carbon energy transitions. Such transformative thinking can gain further momentum through the conceptualization of energy justice beyond existing frameworks and operationalization of energy justice evaluation at the system scale.

\section{AUTHOR CONTRIBUTIONS}

JL conceived of the presented idea. JL and JB developed the conceptual and analytical frameworks, performed the case study analysis, and wrote the manuscript.

\section{ACKNOWLEDGMENTS}

The authors wish to thank the editor and two reviewers for their valuable comments on the manuscript. We also gratefully acknowledge Dr. Job Taminiau of the Foundation for Renewable Energy and Environment for his insightful suggestions and help on the case analysis.

Burke, M. J., and Stephens, J. C. (2017). Energy democracy: goals and policy instruments for sociotechnical transitions. Energy Res. Soc. Sci. 33, 35-48. doi: 10.1016/j.erss.2017.09.024

Byrne, J., Glover, L., and Martinez, C. (2002). “The production of unequal nature," in Environmental Justice: Discourses in International Political Economy, eds J. Byrne, L. Glover, and C. Martinez (New York, NY: Routledge), 261-291.

Byrne, J., and Hoffman, S. M. (1996). "The ideology of progress and globalization of nuclear power," in Governing the Atom: The Politics of Risk, eds J. Byrne, and S. M. Hoffman (New York, NY: Routledge), 11-46.

Byrne, J., Martinez, C., and Ruggero, C. (2009). Relocating energy in the social commons: ideas for a sustainable energy utility. Bull. Sci. Technol. Soc. 29, 81-94. doi: 10.1177/0270467609332315

Byrne, J., Toly, N., and Glover, L. (2006). "Energy as a social project: recovering a discourse," in Transforming Power: Energy, Environment, and Society in Conflict, eds J. Byrne, and N. Toly (New York, NY: Routledge), 1-32.

Byrne, J., Wang, Y.-D., Lee, H., and Kim, J. (1998). An equity- and sustainabilitybased policy response to global climate change. Energy Policy 26, 335-343. doi: 10.1016/S0301-4215(97)00174-2

Cherp, A., Vinichenko, V., Jewell, J., Brutschin, E., and Sovacool, B. (2018). Integrating techno-economic, socio-technical and political perspectives on national energy transitions: a meta-theoretical framework. Energy Res. Soc. Sci. 37, 175-190. doi: 10.1016/j.erss.2017.09.015

Citizens' Nuclear Information Center (CNIC) (2017). Evacuation Orders Lifted for Iitate, Kawamata, Namie, Tomioka. Available online at: http://www.cnic.jp/ english/?p=3855 (accessed June 2, 2018). 
Clark, D. E., and Nieves, L. A. (1994). An interregional hedonic analysis of noxious facility impacts on local eages and property values. J. Environ. Econ. Manage. 27, 235-253. doi: 10.1006/jeem.1994.1036

Coase, R. (1960). The problem of social cost. J. Law Econom. 3, 1-44. doi: $10.1086 / 466560$

Cutter, S. L., Boruff, B.J., and Lynn Shirley, W. (2003). Social vulnerability to environmental hazards. Soc. Sci. Q. 84, 242-261. doi: 10.1111/1540-6237.8402002

David, M. (2018). The role of organized publics in articulating the exnovation of fossil-fuel technologies for intra- and intergenerational energy justice in energy transitions. Appl. Energy 228, 339-350. doi: 10.1016/j.apenergy.2018.06.080

Davis, L. W. (2011). The effect of power plants on local housing values and rents. Rev. Econ. Stat. 93, 1391-1402. doi: 10.1162/REST_a_00119

Faculty of Societal Safety Sciences (2018). The Fukushima and Tohoku Disaster: A Review of the Five-Year Reconstruction Efforts. Cambridge, MA: ButterworthHeinemann.

Folland, S., and Hough, R. (2000). Externalities of nuclear power plants: further evidence. J. Reg. Sci. 40, 735-753. doi: 10.1111/0022-4146.00196

Forsyth, T. (2014). Climate justice is not just ice. Geoforum 54, 230-232. doi: 10.1016/j.geoforum.2012.12.008

Goldthau, A., and Sovacool, B. K. (2012). The uniqueness of the energy security, justice, and governance problem. Energy Policy 41, 232-240. doi: 10.1016/j.enpol.2011.10.042

Ha, Y.-H., and Byrne, J. (2019). The rise and fall of green growth: Korea's energy sector experiment and its lessons for sustainable energy policy. WIREs Energy Environ. 8:e335. doi: 10.1002/wene.335

Heffron, R. J., and McCauley, D. (2014). Achieving sustainable supply chains through energy justice. Appl. Energy 123, 435-437. doi: 10.1016/j.apenergy.2013.12.034

Heffron, R. J., and McCauley, D. (2017). The concept of energy justice across the disciplines. Energy Policy 105, 658-667. doi: 10.1016/j.enpol.2017.03.018

Hobson, K. (2006). Enacting environmental justice in Singapore: performative justice and the green volunteer network. Geoforum 37, 671-681. doi: 10.1016/j.geoforum.2005.08.004

Hughes, T. P. (1983). Networks of Power: Electrification of Western Society, 18801930. Baltimore, MD: The Johns Hopkins University Press.

International Atomic Energy Agency (IAEA) (2007). Arrangements for Preparedness for a Nuclear or Radiological Emergency. Vienna, Austria: International Atomic Energy Agency. Available online at: https://www-pub. iaea.org/MTCD/publications/PDF/Pub1265web.pdf (accessed June 20, 2019).

Jamal, T., and Hales, R. (2016). Performative justice: new directions in environmental and social justice. Geoforum 76, 176-180. doi: 10.1016/j.geoforum.2016.09.014

Jenkins, K., McCauley, D, Heffron, R., and Stephan, H. (2014). Energy justice: a whole systems approach. Queens Polit. Rev. 2, 74-87.

Jenkins, K., McCauley, D, Heffron, R., Stephan, H., and Rehner, R. (2016). Energy justice: a conceptual review. Energy Res. Soc. Sci. 11, 174-182. doi: $10.1016 /$ j.erss.2015.10.004

Ji, S., Cherry, C. R., Zhou, W, Sawhney, R., Wu, Y, Cai, S, et al. (2015). Environmental justice aspects of exposure to PM2.5 emissions from electric vehicle use in China. Environ. Sci. Technol. 49, 13912-13920. doi: 10.1021/acs.est.5b04927

Joroff, A. (2018). Energy Justice: What It Means and How to Integrate It Into State Regulation of Electricity Markets. The Environmental Forum 35. Available online at: https://www.eli.org/the-environmental-forum/energyjustice (accessed September 1, 2018).

Kang, S. (2018). Seoul to Generate 1GW of Energy From Solar by 2022. Available online at: https://www.koreatimes.co.kr/www/nation/2018/11/281_ 259295.html (accessed March 5, 2019).

Kim, J., and Byrne, J. (1996). "The asian atom: hard-path nuclearization in East Asia," in Governing the Atom: The Politics of Risk, eds J. Byrne, and S. M. Hoffman (New York, NY: Routledge), 271-297.

Lee, S.-H., Hwang, J.-T., and Lee, J. (2018). The production of a national riskscape and its fractures: nuclear power facility location policy in South Korea. Erdkunde 72, 185-195. doi: 10.3112/erdkunde.2018.02.07

Luna, M. (2008). Out of sight, out of mind: distancing and the geographic relationship between electricity consumption and production in Massachusetts. Soc. Sci. Q. 89, 1277-1292. doi: 10.1111/j.1540-6237.2008.00578.x
Lyman, E., Schoeppner, M., and von Hippel, F. (2017). Nuclear safety regulation in the post-fukushima era. Science 356, 808-809. doi: 10.1126/science.aal4890

Malik, A., and Tuckfield, B. (2019). Applied Unsupervised Learning With R: Uncover Hidden Relationships and Patterns With k-Means Clustering, Hierarchical Clustering, and PCA. Birmingham: Packt Publishing.

Mannheim, K. (1985). Ideology and Utopia: An Introduction to the Sociology of Knowledge. San Diego, CA: Harcourt Brace Jovanovich.

McCauley, D., Heffron, R., Stephan, H., and Jenkins, K. (2013). Advancing energy justice: the triumvirate of tenets. Int. Energy Law Rev. 32, 1-5.

Messing, M., Paul Friesema, H., and Morell, D. (1979). Centralized power: The Politics of Scale in Electricity Generation. Cambridge: Oelgeschlager, Gunn \& Hain.

Mumford, L. (1934). Technics and Civilization. New York, NY: Harcourt, Brace \& Company.

National Academics of Sciences, Engineering, and Medicine (NASEM) (2016). Lessons Learned from the Fukushima Nuclear Accident for Improving Safety and Security of U.S. Nuclear Plants: Phase 2. Washington DC: The National Academies Press.

National Association for the Advancement of Colored People (NAACP) (2012). Coal Blooded: Putting Profits Before People. Coal Blooded. Available online at: https://www.naacp.org/wp-content/uploads/2016/04/CoalBlooded. pdf (accessed September 1, 2018).

Nuclear Safety and Security Commission (NSSC) (2014). Radiation Emergency Planning Zones. Available online at: http://nsic.nssc.go.kr/nsic.do?nsicKey= 20010605 (accessed May 9, 2019).

O'Donnell, O., van Doorslaer, E., Wagstaff, A., and Lindelow, M. (2008). Analyzing Health Equity Using Household Survey Data: A Guide to Techniques and Their Implementation. Washington, DC: World Bank. https://openknowledge. worldbank.org/handle/10986/6896

Park, J., and Sovacool, B. K. (2018). The contested politics of the Asian atom: peripheralisation and nuclear power in South Korea and Japan. Env. Polit. 27, 686-711. doi: 10.1080/09644016.2018.1439436

Pasqualetti, M. J., and Brown, M. A. (2014). Ancient discipline, modern concern: geographers in the field of energy and society. Energy Res. Soc. Sci. 1, 122-133. doi: 10.1016/j.erss.2014.03.016

Perrow, C. (1984). Normal Accidents: Living With High-Risk Technologies. New York, NY: Basic Books.

Piggot, G. (2018). The influence of social movements on policies that constrain fossil fuel supply. Climate Policy 18, 942-954. doi: 10.1080/14693062.2017.1394255

Richardson, L. (2017). "Protesting policy and practice in South Korea's nuclear energy industry," in Learning from Fukushima: Nuclear Power in East Asia, by Peter van Ness and Mel Gurtov (Canberra: ANU Press), 133-154.

Ryan, S. E., Hebdon, C., and Dafoe, J. (2014). Energy research and the contributions of the social sciencens: a contemporary examination. Energy Res. Soc. Sci. 3, 186-197. doi: 10.1016/j.erss.2014.07.012

Sareen, S., and Haarstad, H. (2018). Bridging socio-technical and justice aspects of sustainable energy transitions. Appl. Energy 228, 624-632. doi: 10.1016/j.apenergy.2018.06.104

Seoul Metropolitan Government (SMG) (2018). New Renewable Energy: One Less Nuclear Power Plant. Available online at: https://seoulsolution.kr/en/content/ 3363 (accessed March 5, 2019).

Sovacool, B.K., Sidortsov, R. V., and Jones, B. R. (2014). Energy Security, Equality and Justice. New York, NY: Routledge.

Sovacool, B. K., and Dworkin, M. H. (2015). Energy justice: conceptual insights and practical applications. Appl. Energy 142, 435-444. doi: 10.1016/j.apenergy.2015.01.002

Sovacool, B. K., Heffron, R.J., McCauley, D., and Goldthau, A. (2016). Energy decisions reframed as justice and ethical concerns. Nat. Energy 1:16024. doi: 10.1038/nenergy.2016.24

Sovacool, B. K., Lovell, K., and Ting, M.B. (2018). Reconfiguration, contestation, and decline: conceptualizing mature large technical systems. Sci. Technol. Human Values 43, 1066-1097. doi: 10.1177/0162243918768074

Sovacool, B. K., Ryan, S. E., Stern, P. C., Janda, K., Rochlin, G., Spreng, D., et al. (2015). Intergrating social science in energy research. Energy Res. Soc. Sci. 6, 95-99. doi: 10.1016/j.erss.2014.12.005

Sowell, T. (1972). Say's Law: An Historical Analysis. Princeton: Princeton University Press. 
Stern, P. C., and Aronson, E. (1984). Energy Use: The Human Dimension. New York, NY: W.H.Freeman and Company.

Temper, L., del Bene, D., and Martinez-Alier, J. (2015). Mapping the frontiers and front lines of global environmental justice: the EJAtlas. J. Polit. Ecol. 22, 255-278. doi: 10.2458/v22i1.21108

Teron, L., and Ekoh, S. S. (2018). Energy democrarcy and the city: evaluating the practice and potential of municipal sustainability planning. Front. Commun. 3, 1-5. doi: 10.3389/fcomm.2018.00008

Touché, G. E., and Rogers, G. O. (2005). Environmental equity and electric power generation: disparate community outcomes within Texas? J. Environ. Plan. Manage. 48, 891-915. doi: 10.1080/09640560500294319

U.S. Environmental Protection Agency (EPA) (2017). EJSCREEN Technical Documentation. Washington, DC: U.S. Environmental Protection Agency. https://www.epa.gov/ejscreen/technical-documentation-ejscreen

U.S. Nuclear Regulatory Commission (NRC) (2017). NRC Regulations Title 10, Part 50, Section 50.47 Emergency Plans. Available online at: https://www.nrc.gov/ reading-rm/doc-collections/cfr/part050/part050-0047.html (accessed May 9, 2019).

United Church of Christ (UCC) (1987). Toxic Wastes and Race in the United States: A National Report on the Racial and Socio-Economic Characteristics of Communities with Hazardous Waste Sites. New York, NY: United Church of Christ.

United Nations Development Programme (UNDP) (2017). Social Vulnerability Assessment Tools for Climate Change and DRR Programming. Istanbul: United Nations Development Programme. Available online at: https://www.adaptationundp.org/Social-Vulnerability-Assessment-Tools (accessed June 20, 2019).
Valentine, S. V., and Sovacool, B. K. (2010). The socio-political economy of nuclear power development in Japan and South Korea. Energy Policy 38, 7971-7979. doi: 10.1016/j.enpol.2010.09.036

Walker, G., and Day, R. (2012). Fuel poverty as injustice: Integrating distribution, recognition and procedure in the struggle for affordable warmth. Eneregy Policy 49, 69-75. doi: 10.1016/j.enpol.2012.01.044

Yun, S.-J. (2017). “Citizen participation-based energy transition experiments in a megacity: the case of the one less nuclear power plant in Seoul, South Korea," in Energy Transition in East Asia: A Social Science Perspective, by Kuei-Tien Chou (London: Routledge), 77-103.

Yun, S.-J., Byrne, J., Baker, L., Bond, P., Kaufmann, G., Luhmann, H.-J., et al. (2018). "Energy and climate change," in Rethinking Environmentalism: Linking Justice, Sustainability, and Diversity, eds S. Lele, E. S. Brondizio, J. Byrne, G. M. Mace, and J. Martinez-Alier (Cambridge, MA: MIT Press), 205-223.

Conflict of Interest Statement: The authors declare that the research was conducted in the absence of any commercial or financial relationships that could be construed as a potential conflict of interest.

Copyright (c) 2019 Lee and Byrne. This is an open-access article distributed under the terms of the Creative Commons Attribution License (CC BY). The use, distribution or reproduction in other forums is permitted, provided the original author(s) and the copyright owner(s) are credited and that the original publication in this journal is cited, in accordance with accepted academic practice. No use, distribution or reproduction is permitted which does not comply with these terms. 